\title{
An Artificial Neural Network Model Based on Experimental Measurements for Estimating the Grounding Resistance
}

\author{
Ahmet Kayabasi ${ }^{1,(D)}$, Berat Yildiz ${ }^{1,2, *}$, (D), Selami Balci ${ }^{3}$, (D) \\ ${ }^{1}$ Karamanoglu Mehmetbey University, Department of Electrical and Electronics Engineering, Karaman, Turkey; \\ ${ }^{2}$ Konya Technical University, Department of Electrical and Electronics Engineering, Konya, Turkey; \\ ${ }^{3}$ Karamanoglu Mehmetbey University, Department of Electrical and Electronics Engineering, Karaman, Turkey;
}

\begin{abstract}
In grounding systems established in rocky and sandy lands where contact resistance with metal electrodes is high, contact resistance is generally the most critical parameter that changes the total grounding resistance value. Therefore, the nonlinear variation of the earth contact resistance according to the soil type cannot be taken into account in determining the grounding resistance with the traditional mathematical formulas given theoretically. This reduces the accuracy of grounding resistance determination. In this study, experimental measurements were made according to soil types and a data set was created. Then, to estimate the total grounding resistance of complex grounding systems, a classification was made using the multi-layer sensor (MLP) type ANN algorithm and the successful results were reported. Thus, according to the data set prepared based on experimental measurements, the proposed general classification algorithm approach can be applied to any grounding system. It presents a different technique from the previous literature as a pre-feasibility study for estimating the grounding resistance, especially before the grounding system installation, which is an early stage of the design process.
\end{abstract}

Keywords: Grounding systems, grounding resistance measurement, parameter classification, soil type.

\section{Introduction}

Today, electrical energy, as an indispensable type of energy, is vital in daily life, and possibly electrical and insulation faults that may occur during the use of electrical energy can pose a danger to the life of living things. Therefore, various protection measures such as grounding, insulation, and the use of low voltage must be taken to protect the life of living things and the system in electrical installations [1]. Grounding systems, an extremely safe protection measure, are the critical components of the protection system against lightning and fault currents of facilities, substations, transmission, and distribution lines in general electrical installations. These systems are primarily designed for ground fault conditions at mains frequency values and transfer highvalue leakage currents ( $30 \mathrm{~mA}$ and above) to the ground. Thus, grounding systems that are correctly installed and follow the reliable requirements of the relevant international standards can safely distribute high-value fault currents to the ground; in this way, it protects life and property from harm and damage. In infield application, all elements of the grounding system are interconnected. They can perform their duty to safely transfer both power frequency faults and lightning impulse currents to the ground. On the other hand, for a grounding system to function effectively, the ground resistance value must be kept at low levels during the use of the electrical facility.

The international standards [2] specify the effects of meteorological issues such as humidity, temperature, and soil compaction on soil resistivity and recommend periodic measurement of soil resistance values to keep them under control. However, most electrical installations in rocky areas require high costs in installing grounding systems, from lack of suitable location or preventing installation. Besides, the ground resistivity of the top layer is subject to seasonal changes due to weather conditions such as precipitation, ice, and air temperature, which mainly affect ground moisture. At the same time, the percentage of dissolved salt and soil consistency plays an essential role. The effect of ground resistivity $(\rho)$ on the value of ground transition resistance $(R g)$ is very high. It varies depending on humidity, temperature, salt content, soil type, which differs significantly seasonally throughout the year. In addition, ground resistance reaches very high values in the summer months when the moisture in the ground layers decreases [3]. In recent years, the use of ground reformative compounds to soften the ground, resulting in reduced ground resistance, has been increasingly popular in engineering. Those are generally used in high resistive ground types and must fully comply [4]. Therefore, numerous research studies have been conducted in the past literature examining and observing the performance of these materials and their effects on the ground resistance of various grounding systems [5].

In this study, unlike other studies, an experimental data set consisting of 200 data was created to determine the nonlinear changes of the grounding resistance with complex dry-stony and wet-stone free soil structures.

\footnotetext{
*Corresponding author

E-mail address:yildizberat2086@gmail.com
}

Received: 31/Oct/2021; Received in revised form: 06/Feb/2022; Accepted: 10/Feb/2022. 
This data set was trained using multilayer perceptron (MLP) type ANN, and successful results were obtained in estimating the classification of grounding resistance of complex grounding systems.

The remaining content of the article is organized as follows. A general literature review about artificial intelligence techniques applied in grounding systems is explained in the second part. The third part gives the applied methods and the materials used. Obtained results are interpreted in the fourth chapter. In the fifth, that is, the conclusion part, the results of the article, and future studies are mentioned.

\section{Related Work}

The value of the ground resistance varies greatly depending on the grounding system and the characteristics of the ground in which the system is buried. Considering that ground resistivity fluctuates depending on the season during the year, there is no definite value for ground resistance. In [6], it was aimed to develop a methodological approach to predict soil resistivity using artificial intelligence techniques. For this, linear and nonlinear relationships between various parameters are defined using Artificial Neural Networks (ANNs). In a study using ANN [3], based on temperature and precipitation measurements for a year, tests were conducted with various algorithms for their ability to predict soil resistance, and an optimization procedure was proposed to select the parameters of each training algorithm. Thus, the effectiveness of the ANN is proven by the high correlation index between the estimated and measured values of the ground resistance. In another study on meteorological data [7], a suitable genetic programming methodology was used to model and predict the measurement results of grounding resistance values in the field. The experimental data carried out in this context were field measurements in Greece for approximately four years. An intelligent approach based on Gene Expression Programming (GEP) was proposed, and additionally, five linear regression models were applied to a specially selected data set. The obtained results showed that evolutionary techniques such as those based on Genetic Programming (GP) are promising for predicting ground resistance.

It is of great importance for electrical engineers to provide as low as possible values for grounding resistance during the design phase and the life cycle of the grounding system. In case of high ground resistivity values or insufficient space for installing grounding systems, a commonly used technique to reduce the grounding resistance value is the use of ground-reinforcing custom-made compounds. For this purpose, in a study conducted in the past literature [8], a particular methodology developed with ANN to determine the grounding resistance of naturally buried grounding electrodes using soil enrichment compounds under various meteorological conditions is proposed.

In the studies conducted to determine the soil resistance value in the past literature [5], entropy knowledgebased inductive learning techniques are recommended for testing the performance of grounding systems according to ground resistance and precipitation data estimating possible changes in ground resistance values. For this purpose, ground resistivity and precipitation density measurements were made at various ground depths in a particular university campus area over four years. Ground resistance values of several grounding rods coated with ground strengthening compounds were obtained as a function of time. Decision trees were created to approximate the ground resistance to the discrete-valued target function to model these obtained data. They were represented by production rules to make the model understandable. The v-fold cross-validation approach determined error rates and performance of the model on invisible states. Thus, inductive machine learning primarily aims to achieve high accuracy, not as a classifier and is used more as a knowledge discovery tool that can be controlled with statistical techniques.

The proposed model in [9] consists of a Wavelet Neural Network trained and validated by field measurements performed for the last three years. Soil reinforcement compounds and several ground rods placed in natural soil were tested to obtain a large dataset for training the network covering various soil conditions. Thus, this study introduces wavelet analysis in ground resistance estimation and tries to benefit from the benefits of artificial intelligence.

An estimator for the grounding resistance value is proposed to study the grounding electrodes' total length and geometric properties [10]. This proposed approach is valid for a ground-embedded electrode system that can be considered almost homogeneous with various assumptions. It is generally confirmed that more accurate resistance estimation can be made as the size of the electrodes gets larger.

The study [11] aimed to derive simple formulas for predicting the grounding resistance value of wind farms installed in terrains that can be designed with a two-layer grounding system. Different combinations of grounding resistance values for the top and bottom layer of two-layer grounding systems and the depth of the top layer are carefully determined to cover a wide variety of irregularities in the earth. Then, the grounding resistance values are selected from the simulation studies run for a combination between the investigated bilayer models and the predefined ground electrode geometry.

It is known that the grounding systems are a crucial component for the safe operation of the electrical grid, transmission, distribution, and electrical power systems in general. However, the researchers have limited knowledge of the soil resistance variation of the region at the design stage. In addition, the grounding resistance periodical measurement is often hampered by residential infra-structure. Therefore, a model has been 
developed in [12] that correctly describes the dynamics of grounding resistance variation based on the engineers' need for the flexibility and reliability of determining the behavior of the grounding systems. Thus, the developed model has trained in-field soil resistivity and precipitation height measured over four years from a nonlinear and non-parametric wavelet neural network (WNN). Next, the proposed framework was tested with different ground reinforcing compounds in five (5) other grounding systems. The obtained research results show that WNN can create an accurate model for soil resistance estimation and can be a valuable tool for electrical engineers.

A precondition for the correct and reliable grounding system design is full knowledge of the earth structure at the installation region. Engineers can show the ground profile, the most critical parameter for designing a grounding system and determining the maximum allowable step and touch voltage limits thanks to ground resistivity measurements. In [13], it highlights the importance and necessity for engineers to select appropriate ground resistivity measurement axes in the terrain of interest and correct measurement depths and combinations of axes for the final determination of the earth profile. In this context, it is also proven that appropriate and preplanned measurement of ground resistance, especially in the non-isotropic ground, is of great importance for the precise design of a safe grounding system.

The primary purpose of the work in [14] is to investigate the prediction of soil resistance change during a year using ANN. An ANN modeling was carried out with the different algorithms using earth (soil) resistivity and experimental precipitation data to select the optimum training algorithm and related parameters and determine the behavior of the soil resistivity of a single rod. Thus, the high value of the correlation index of the modeled and experimental values indicates the high efficiency of the ANN. The proposed methodology based on ANN has been a valuable tool for estimating grounding resistance throughout the year despite the challenges in measuring its value.

In this study, experimental measurements were made to determine the nonlinear variation of the grounding resistance value according to the soil type. Then, a classification has been made to estimate the grounding resistance values of complex grounding systems, and the results have been reported.

\section{Method and Material}

In rocky and sandy lands where the contact resistance is high in grounding systems established using copper electrodes in general, contact resistance is the most critical parameter that generally changes the total grounding resistance value. In this context, since the ground contact resistance value cannot be considered exact, the degree of accuracy in determining the grounding resistance with the traditional mathematical formulas given theoretically is not very high. In this section, firstly, information about the measurement of grounding resistance value as an experimental study used to create the data set is given. Then, the artificial intelligence technique approach used to classify the obtained data set is explained.

\subsection{Ground resistivity measurements}

Two-point and four-point methods are frequently used in electrical installations to measure the ground resistance value experimentally. The four-point method (Wenner) is the most accurate in practice [12], [16]. Therefore, the Wenner method was applied in the measurements in the experimental part of this study. As shown in Figure 1, four $50 \mathrm{~cm}$ long electrodes were buried in the ground at equal distances from each other at depth $\mathrm{b}$ in the measurements made.

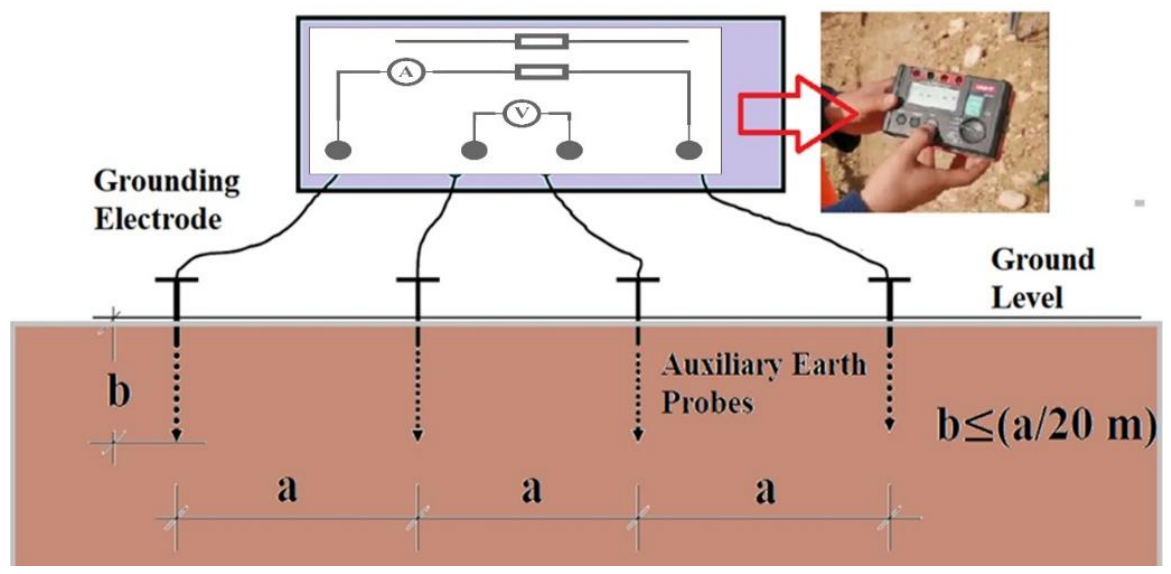

Figure 1. Principle diagram of measurement with the Wenner method [15]

Thus, a test current (I) flows into two electrodes, and the potential (V) between two medium electrodes is measured. The V/I ratio gives the visible resistance $\mathrm{R}(\Omega)$. The visual ground resistance value can be approximately provided by Eq. (1) [2] with mathematical expression. 
$\rho=\frac{4 \pi a R}{1+2 a / \sqrt{a^{2}+4 b^{2}}-a / \sqrt{a^{2}+b^{2}}}$

Here, the distance a must be at least $20 \mathrm{~m}$, with $\mathrm{b} \leq(\mathrm{a} / 20)$. R gives the measured resistance value, and $\rho$ offers the specific earth resistance value in $\Omega \mathrm{m}$. This measurement should be made with the four-probe method, and unique devices used in experimental studies have been developed to apply the Wenner Method in practice. The measurement principle is that a voltage of up to $150 \mathrm{~Hz}$ is applied between the outer electrodes. The voltage between the inner probes due to the current flowing is measured. The specific earth resistance is calculated using the resistance value calculated from the measured voltage and current value with the intermediate distance value. In advanced earth resistance measuring instruments, the specific resistance is directly read from the screen by entering the distance between the electrodes. The voltage frequency to be applied should be variable to eliminate the effect of other currents in the ground at the measurement site.

\subsection{ANN model}

ANN is a sub-branch of artificial intelligence that collects examples and generalizes [17-18]. It can classify by comparing the linear or nonlinear relations obtained from the samples with the data it has never encountered before [19]. Thanks to its learning and generalization functions, ANN is involved in many scientific studies and can offer solutions to complex problems [20-25]. The ANN structure consists of three essential layers: input, output, and hidden layers. The information processing function is performed in these layers, where each neuron is connected to other neurons by weight values (Figure 2).

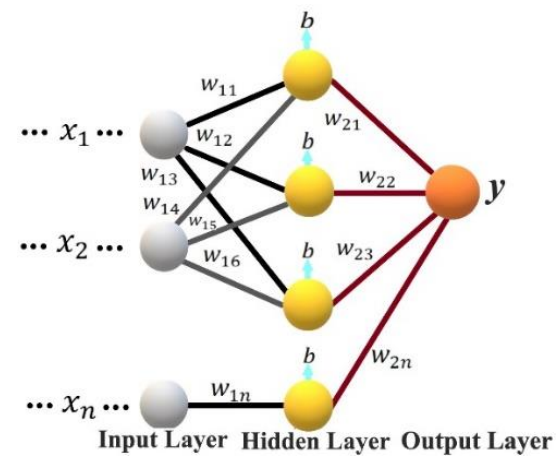

Figure 2. The basic ANN structure

The different values data set is transmitted directly to the input layer during the training and testing phases. Then, mathematical operations such as addition, multiplication, and activation functions are applied in the hidden layers. Finally, this data is transmitted to the output layer. The difference between the input and output layers is minimized by associating them with the mathematical expressions applied in the hidden layers. As this difference decreases, the learning function is performed. More than one hidden layer may be used depending on the complexity between the input and output data. The outputs of the neurons in the layers are formed by the expression given in Eq. (2).

$y=f\left(\sum_{i=1}^{n} x_{i} w_{i j}+b\right)$

Here, the input parameters presented to the network are $x_{i}$, the weight values $w_{i}$ produced by the network according to the output value, the bias value $b$, the activation function $f($.$) , and the output value yi.$

Perceptrons are unsuccessful in solving problems that cannot be classified linearly. MLP is a multi-layered network that works particularly well in nonlinear classification and generalization situations. Learning in this type of network is based on the Delta Learning Rule. The main purpose of this rule is to minimize the error between the expected output of the network and the output it produces. Since it does this by spreading the error to the network, this network is called the error propagation network. In this study, the previously collected grounding resistance data which are non-linear were trained and classified using multilayer perceptron (MLP) type ANN. There are two classes in the dataset: Dry and Stony ground resistance labeled with 1 and Wet and Stone Free ground resistance labeled with 2. Each class contains 100 measured data. The training was carried out using the ANN structure given in Figure 3. 'logsig' (Logarithmic Sigmoid), 'logsig', and 'purelin' activation functions are used in the hidden layers of this network structure, which imparts nonlinear behavior to layer inputs, respectively. In addition, the parameters of the network architecture such as Adapt Function and Training Function which are given in Table 1, were chosen to overcome the Vanishing and Exploding gradient problems and to prevent the memorization of the network. 


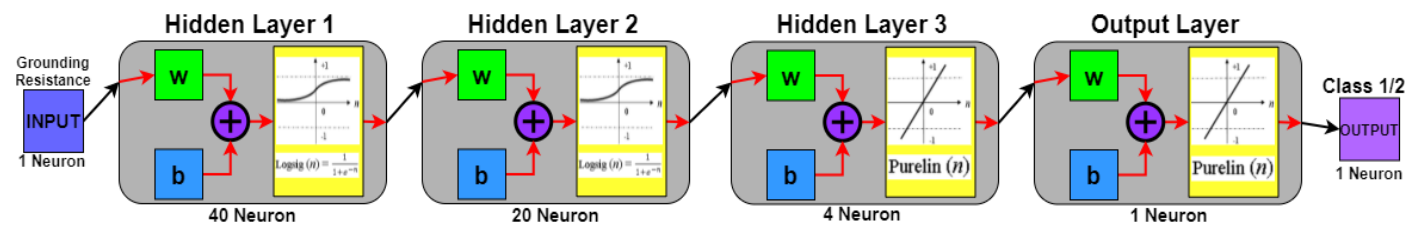

Figure 3. ANN structure used in classification.

Table 1. Model Parameters

\begin{tabular}{|l|l|}
\hline Parameters & Values/Types \\
\hline Adapt Function & $\begin{array}{l}\text { 'adaptwb' } \\
\text { (Adapt network with weight and bias learning rules) }\end{array}$ \\
\hline Activation Functions & 'logsig', 'logsig', 'purelin' \\
\hline Epochs & 10000 \\
\hline Hidden Layers (HL) & 3 \\
\hline HL Neurons & $40,20,4$ \\
\hline Performance Function & $\begin{array}{l}\text { 'mse' } \\
\text { (Mean Squared Error) }\end{array}$ \\
\hline Train Function & $\begin{array}{l}\text { 'traingdx' } \\
\text { (Gradient Descent with Momentum and Adaptive Learning Rate) }\end{array}$ \\
\hline
\end{tabular}

\section{Discussion and Results}

Regression analysis is frequently used to describe the relationship between more than one variable and determine how effective the relationship between variables is. In the study, the classification process with ANN was made by analogy with the regression problems. Here, dry and stony soil is labeled 1, wet and stone-free soil 2. Therefore, regression analysis was used to define the relationship between soil structure and grounding resistance. The regression curves obtained as a result of the training and tests applied are given in Figure 4.
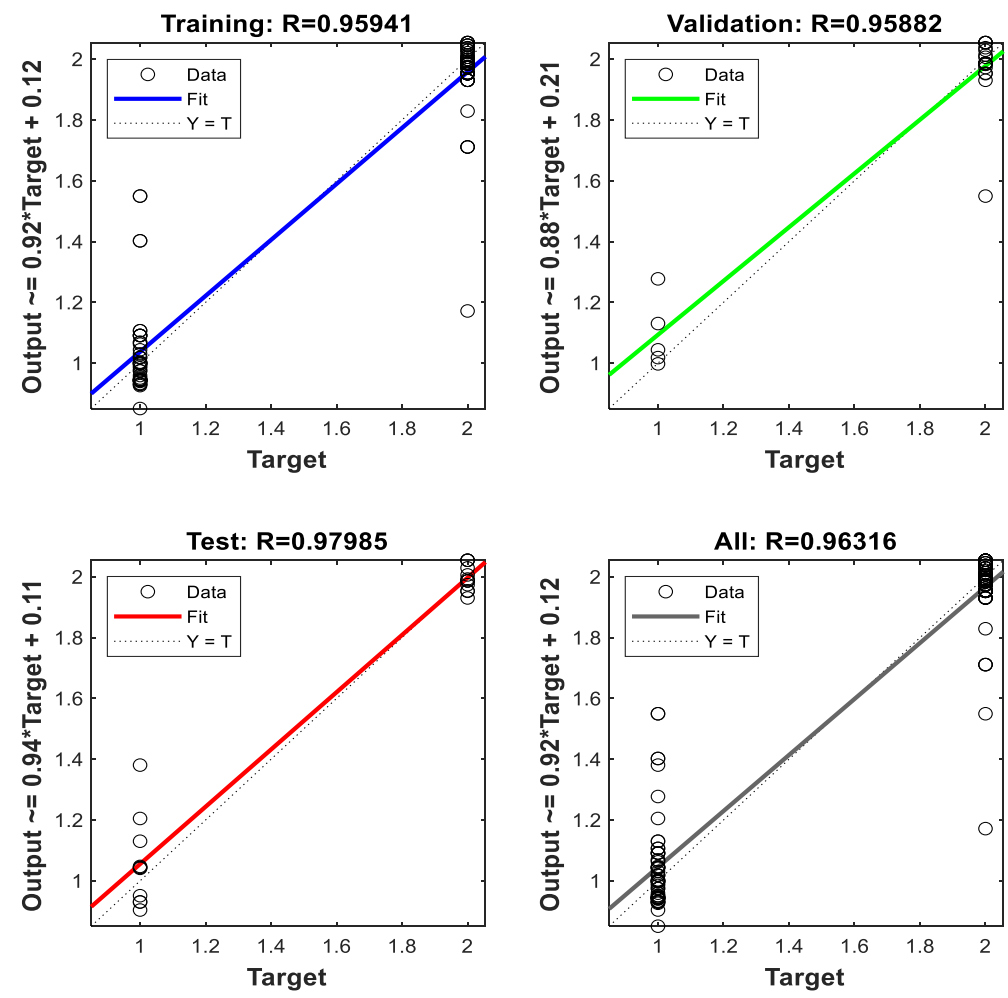

Figure 4. The regression curve

As can be seen from the curves formed, there is a strong relationship between the variables. When training, testing, and validation results are correlated in classification accuracy, the correlation coefficient (R) is over 0.9. Again, with the same results, when the mean square error (MSE) was calculated, very low values such as 0.014 were obtained in Figure 5. 


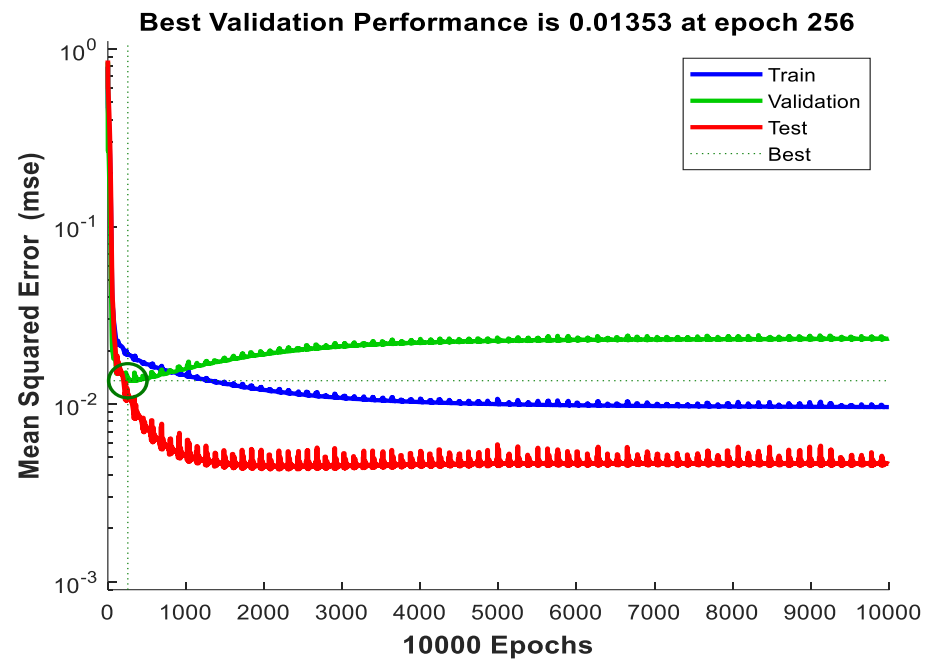

Figure 5. Training, test, and validation MSE

Therefore, the classification process is very efficient in training, testing, and validation. In addition, Figure 6 presents a graph showing the gradient curve, the validation checks, and the adaptive learning rate used during training, which are among the network parameters.
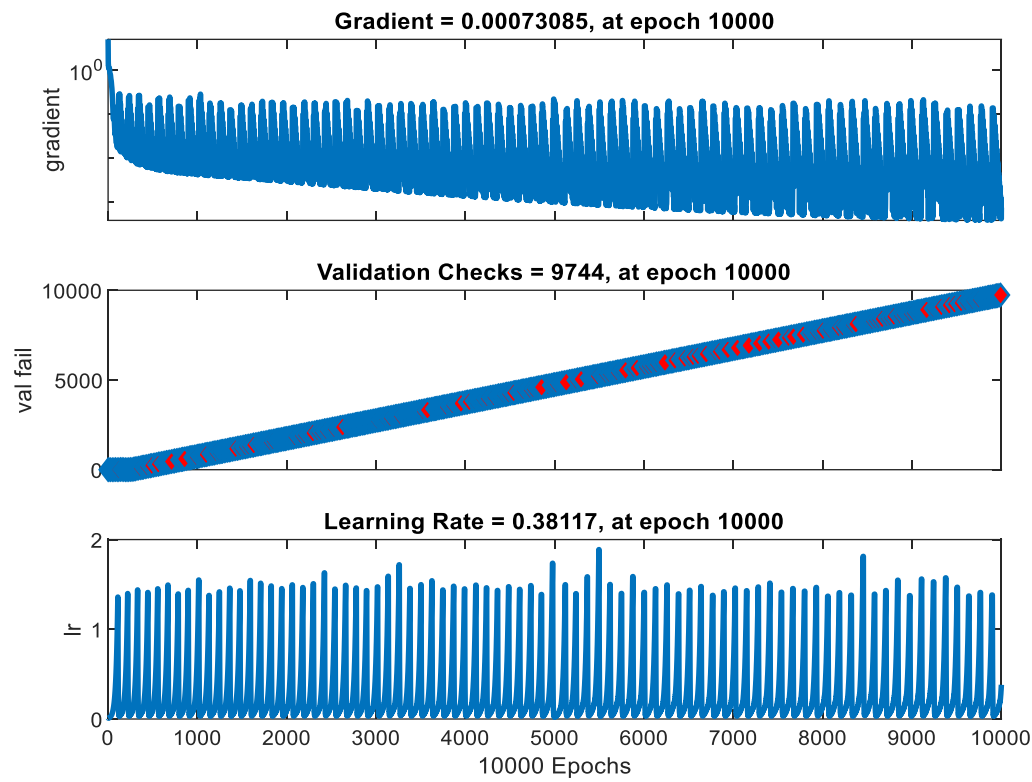

Figure 6. Change in network parameters during training

The applied classification test was performed on 40 random data that were not trained in the network structure before. The first group expresses the dry and stony soil structure in the classification, while the second group expresses the wet and stone-free soil structure. As a result of the tests, only 1 out of 40 data was classified incorrectly. Numerical Accuracy (3) and Mean Absolute Error (4) equations were used for performance evaluation as a result of training and testing.

$\operatorname{Accuracy}(\%)=100 \times\left[1-\left|\frac{(\text { Target }- \text { Output })}{\text { Target }}\right|\right]$

$M A E=\frac{\sum(\text { Target }- \text { Output })}{\text { Number of Test Data }}$

Therefore, the classification error is around $2.5 \%$. The classification performance results of the data set used as test data are given in Table 2. Values with incorrect classification are marked in bold. 
Table 2. Classification Performance

\begin{tabular}{|c|c|c|c|c|c|c|c|}
\hline \# & $\begin{array}{l}\text { Test Input } \\
\text { Data }(\Omega \mathrm{m})\end{array}$ & $\begin{array}{l}\text { Test Output } \\
\text { Data }(1 / 2)\end{array}$ & $\begin{array}{l}\text { Numerical } \\
\text { Output }\end{array}$ & $\begin{array}{l}\text { Numerical } \\
\text { Accuracy } \%\end{array}$ & $\begin{array}{l}\text { Absolute. } \\
\text { Error }\end{array}$ & $\begin{array}{l}\text { Prediction } \\
\text { of ANN }\end{array}$ & Classification \\
\hline 1 & 16 & 1 & 1.1303 & 86.97 & 0.13031 & 1 & Dry-Stone \\
\hline 2 & 77 & 1 & 0.9471 & 94.71 & 0.05291 & 1 & Dry-Stone \\
\hline 3 & 15 & 2 & 1.1717 & 58.6 & 0.82828 & 1 & Wet-Stoneless \\
\hline 4 & 1 & 2 & 1.9866 & 99.33 & 0.01338 & 2 & Wet-Stoneless \\
\hline 5 & 45 & 1 & 1.0913 & 90.87 & 0.09131 & 1 & Dry-Stone \\
\hline 6 & 36 & 1 & 1.0034 & 99.66 & 0.00341 & 1 & Dry-Stone \\
\hline 7 & 17 & 1 & 1.0909 & 90.91 & 0.09094 & 1 & Dry-Stone \\
\hline 8 & 1 & 2 & 1.9866 & 99.33 & 0.01338 & 2 & Wet-Stoneless \\
\hline 9 & 51 & 1 & 0.8508 & 85.1 & 0.14915 & 1 & Dry-Stone \\
\hline 10 & 5 & 2 & 1.9829 & 99.15 & 0.01706 & 2 & Wet-Stoneless \\
\hline 11 & 2 & 2 & 1.9522 & 97.61 & 0.04777 & 2 & Wet-Stoneless \\
\hline 12 & 0.7 & 2 & 2.0062 & 99.69 & 0.00617 & 2 & Wet-Stoneless \\
\hline 13 & 0.9 & 2 & 1.9927 & 99.63 & 0.00733 & 2 & Wet-Stoneless \\
\hline 14 & 0.1 & 2 & 2.0544 & 97.28 & 0.05437 & 2 & Wet-Stoneless \\
\hline 15 & 9 & 2 & 1.7112 & 85.56 & 0.28883 & 2 & Wet-Stoneless \\
\hline 16 & 6 & 2 & 1.9723 & 98.62 & 0.02766 & 2 & Wet-Stoneless \\
\hline 17 & 1 & 2 & 1.9866 & 99.34 & 0.01338 & 2 & Wet-Stoneless \\
\hline 18 & 22 & 1 & 0.9333 & 93.33 & 0.06672 & 1 & Dry-Stone \\
\hline 19 & 17 & 1 & 1.0909 & 90.91 & 0.09094 & 1 & Dry-Stone \\
\hline 20 & 0.2 & 2 & 2.0459 & 97.71 & 0.04594 & 2 & Wet-Stoneless \\
\hline 21 & 34 & 1 & 1.0574 & 94.26 & 0.05743 & 1 & Dry-Stone \\
\hline 22 & 21 & 1 & 0.9511 & 95.11 & 0.04888 & 1 & Dry-Stone \\
\hline 23 & 1 & 2 & 1.9866 & 99.33 & 0.01338 & 2 & Wet-Stoneless \\
\hline 24 & 70 & 1 & 1.0017 & 99.83 & 0.00170 & 1 & Dry-Stone \\
\hline 25 & 3 & 2 & 1.9540 & 97.67 & 0.04602 & 2 & Wet-Stoneless \\
\hline 26 & 26 & 1 & 1.0183 & 98.17 & 0.01834 & 1 & Dry-Stone \\
\hline 27 & 0.4 & 2 & 2.0293 & 98.53 & 0.02931 & 2 & Wet-Stoneless \\
\hline 28 & 42 & 1 & 0.9593 & 95.93 & 0.04066 & 1 & Dry-Stone \\
\hline 29 & 23 & 1 & 0.9429 & 94.3 & 0.05706 & 1 & Dry-Stone \\
\hline 30 & 4 & 2 & 1.9740 & 98.7 & 0.02601 & 2 & Wet-Stoneless \\
\hline 31 & 35 & 1 & 1.0411 & 95.9 & 0.04108 & 1 & Dry-Stone \\
\hline 32 & 318 & 1 & 1.2393 & 76.1 & 0.23929 & 1 & Dry-Stone \\
\hline 33 & 6 & 2 & 1.9723 & 98.62 & 0.02766 & 2 & Wet-Stoneless \\
\hline 34 & 0.1 & 2 & 2.0544 & 97.3 & 0.05437 & 2 & Wet-Stoneless \\
\hline 35 & 0.4 & 2 & 2.0293 & 98.53 & 0.02931 & 2 & Wet-Stoneless \\
\hline 36 & 4 & 2 & 1.9740 & 98.7 & 0.02601 & 2 & Wet-Stoneless \\
\hline 37 & 18 & 1 & 1.0684 & 93.2 & 0.06840 & 1 & Dry-Stone \\
\hline 38 & 82 & 1 & 0.9262 & 92.62 & 0.07380 & 1 & Dry-Stone \\
\hline 39 & 25 & 1 & 1.0043 & 99.57 & 0.00433 & 1 & Dry-Stone \\
\hline 40 & 2 & 2 & 1.9522 & 97.61 & 0.04777 & 2 & Wet-Stoneless \\
\hline \multicolumn{5}{|c|}{ Average Numerical Accuracy $=\% 94.61$} & MAE $=0.07$ & \multicolumn{2}{|c|}{ Avg. Class. Error $=\% 2.5$} \\
\hline
\end{tabular}

\section{Conclusions and Future Work}

Grounding systems, which must be used as the primary measure in protecting electrical installations, are a vital issue in electrical engineering regarding pre-feasibility studies, operations during installation, and postinstallation reliability. The nonlinear variation of the soil contact resistance according to the soil type plays an essential role in determining the grounding resistance with the theoretical mathematical formulas, especially in the pre-feasibility studies of the grounding systems established in rocky and sandy areas. In addition, it becomes difficult to predict and follow the behavior of the grounding resistance after installation. Therefore, a grounding system must provide a low resistance path to fault current, protect living things from electric shocks caused dangerous steps and touch voltages, and reduce damage to electrical equipment.

In this study, experimental measurements were made with a measuring instrument based on the Wenner Method according to soil types, and a data set regarding soil resistance values was created. This data set was trained in MLP type ANN network, and classification was made between grounding resistances. The soil types depending on the grounding resistance were mainly determined with the classification process. Classification error is around $2 \%$ in tests performed with samples taken out of the data set. The error rate of the proposed approach is close to the error rates of simple soil structures in the literature. Since the experimental measurements made within the scope of this study belong to very complex soil structures, the success rate 
obtained is relatively sufficient. Therefore, the estimations to be made with artificial intelligence methods before going to the field to determine grounding resistance provide significant benefits in terms of cost and time. Moreover, the proposed general classification algorithm approach can be applied to any grounding system according to the data set based on experimental measurements. In future studies, to determine the behavior of the grounding systems of wind power plants, which are generally established in rocky areas, under different meteorological conditions, a study including long-term measurements at certain intervals can be carried out.

\section{Acknowledgments}

We would like to thank the company "Karaman Akar Mühendislik Sanayi ve Tic. Ltd. Şti / Karaman/Turkey" for supporting the experimental studies within the scope of university-industry cooperation for the measurement of grounding resistance.

\section{Declaration of interest}

This article was presented as orally at the ICAIAME 2021 conference.

\section{References}

[1] Balc1 S, Helvac1, ÖA. "Comparative simulation on the grounding grid system of a wind turbine with FEA software", Journal of Energy Systems (2019) 148-157.

[2] “ANSI/IEEE Std 81-1983”, IEEE Guide for Measuring Earth Resistivity, Ground Impedance, and Earth Surface Potentials of a Ground System (1983).

[3] Asimakopoulou FE, Kourni EA, Kontargyri VT, Tsekouras GJ, Stathopulos IA. "Artificial neural network methodology for the estimation of ground resistance", In Proc. 15th WSEAS International Conference on Systems (2011, July) 453-458.

[4] “EN 62561-7:2012”, Lightning Protection System Components (LPSC) - Part 7: Requirements for earthing enhancing compounds (2012, Jan.).

[5] Androvitsaneas VP, Gonos IF, Dounias GD, Stathopulos I. "Ground resistance estimation using inductive machine learning”, In 19th Int. Symp. High Voltage Engineering (2015, August). Pilsen, Czech Republic.

[6] Asimakopoulou FE, Tsekouras GJ, Gonos IF, Stathopulos IA. "Artificial neural network approach on the seasonal variation of soil resistance", In 2011 7th Asia-Pacific International Conference on Lightning (2011, November). 794-799; doi: 10.1109/APL.2011.6110235.

[7] Boulas K, Androvitsaneas VP, Gonos IF, Dounias G, Stathopulos IA. "Ground resistance estimation using genetic programming”, In Proc. 5th Int. Symp. 27th National Conf. Operational Research (2016, June) 66-71. Greece, Athens.

[8] Androvitsaneas VP, Asimakopoulou FE, Gonos IF, Stathopulos IA. "Estimation of ground enhancing compound performance using artificial neural network", In 2012 International Conference on High Voltage Engineering and Application (2012, September) 145-149; doi: 10.1109/ICHVE.2012.6357068.

[9] Androvitsaneas VP, Gonos IF, Stathopulos IA, Alexandridis AK, Dounias G. "Wavelet neural network for ground resistance estimation", In 2014 ICHVE International Conference on High Voltage Engineering and Application (2014, September) 1-5; doi: 10.1109/ICHVE.2014.7035419.

[10] Denche G, Faleiro E, Asensio G, Moreno J. “An Estimator of the Resistance of Large Grounding Electrodes from Its Geometric Characterization”, Applied Sciences 10(22) (2020) 8162; doi: 10.3390/app10228162.

[11] Kondylis GP, Damianaki KD, Androvitsaneas VP, Gonos IF. "Simplified formulae method for estimating wind turbine generators ground resistance", IEEE Transactions on Power Delivery 33(6) (2018) 2829-2836; doi: 10.1109/TPWRD.2018.2839061.

[12] Androvitsaneas VP, Alexandridis AK, Gonos IF, Dounias GD, Stathopulos IA. "Wavelet neural network methodology for ground resistance forecasting”, Electric Power Systems Research 140 (2016) 288-295; doi: 10.1016/j.epsr.2016.06.013.

[13] Faleiro E, Asensio G, Moreno J. "An estimate of the uncertainty in the grounding resistance of electrodes buried in two-layered soils with non-flat surface", Energies 10(2) (2017) 176; doi: 10.3390/en10020176.

[14] Asimakopoulou FE, Kontargyri VT, Tsekouras GJ, Gonos IF, Stathopulos IA. "Estimation of the earth resistance by Artificial Neural Network model", IEEE Transactions on Industry Applications 51(6) (2015) 5149-5158; doi: 10.1109/TIA.2015.2427114.

[15] İlisu İÖ, "Grounding Against Indirect Touch in Electrical Facilities", Chamber of Electrical Engineers Continuing Education Center (EMO) EG/2010/1.

[16] Salam MA, Rahman QM, Ang SP, Wen F. "Soil resistivity and ground resistance for dry and wet soil", Journal of Modern Power Systems and Clean Energy 5(2) (2017) 290-297.

[17] Zupan J. "Introduction to artificial neural network (ANN) methods: what they are and how to use them", Acta Chimica Slovenica 41 (1994) 327-327.

[18] Uhrig RE. "Introduction to artificial neural networks", In Proceedings of IECON'95-21st Annual Conference on 
IEEE Industrial Electronics 1 (1995, November) 33-37. IEEE.

[19] Kayabasi A, Yildiz B, Aslan MF, Durdu A. "Comparison of ELM and ANN on EMG signals obtained for control of robotic-hand", In 2018 10th International Conference on Electronics, Computers and Artificial Intelligence (ECAI) (2018, June) 1-5. IEEE.

[20] Y1lmaz I, Yuksek AG. “An example of artificial neural network (ANN) application for indirect estimation of rock parameters", Rock Mechanics and Rock Engineering 41(5) (2008) 781-795.

[21] Benghanem M, Mellit A, Alamri SN. "ANN-based modeling and estimation of daily global solar radiation data: A case study", Energy conversion and management 50(7) (2009) 1644-1655.

[22] Anuradha B, Reddy VV. "ANN for classification of cardiac arrhythmias", ARPN Journal of Engineering and Applied Sciences 3(3) (2008) 1-6.

[23] Kumar V, Sachdeva J, Gupta I, Khandelwal N, Ahuja CK. "Classification of brain tumors using PCA-ANN", In 2011 world congress on information and communication technologies (2011, December) 1079-1083. IEEE.

[24] Abiodun, OI, Jantan A, Omolara AE, Dada KV, Mohamed NA, Arshad H. "State-of-the-art in artificial neural network applications: A survey”, Heliyon 4(11) (2018) e00938.

[25] Abiodun OI, Jantan A, Omolara AE, Dada KV, Umar AM, Linus OU, ... Kiru MU. "Comprehensive review of artificial neural network applications to pattern recognition", IEEE Access 7 (2019) 158820-158846. 